\title{
Study of infective morbidity following gynecological surgeries
}

\author{
Satyajit P. Gavhane, Vidyadhar B. Bangal*, Swati D. Gagare, Amey R. Kodlikeri
}

Department of Obstetrics and Gynecology, Rural Medical College, Pravara Institute of Medical Sciences, Loni, Maharashtra, India

Received: 20 March 2018

Accepted: 21 April 2018

\section{*Correspondence:}

Dr. Vidyadhar B. Bangal,

E-mail: vbb217@rediffmail.com

Copyright: () the author(s), publisher and licensee Medip Academy. This is an open-access article distributed under the terms of the Creative Commons Attribution Non-Commercial License, which permits unrestricted non-commercial use, distribution, and reproduction in any medium, provided the original work is properly cited.

\begin{abstract}
Background: Post-operative wound infection is a common nosocomial infection all over the world. It is responsible for increase in physical and psychological stress to the patient. It also increases the cost of treatment due to prolonged hospitalization. Present study was carried to find out the post-operative wound infection, morbidity and the risk factors.

Methods: Prospective cross sectional study was carried out at tertiary care teaching hospital for a period of six months. Consecutive 57 cases of surgical site infections (SSI) following obstetric and gynecological abdominal surgery were analyzed.

Results: It was observed that the incidence of SSI was 2.8 percent. Overweight, previous laparotomy scars, emergency surgery and prolong labour were the common risk factors associated with the development of SSI. Certain epidemiological and environmental factors like under nutrition, rural area residence, poverty, illiteracy, ignorance, poor general hygiene, Surgical site infections(SSI) were more commonly observed following emergency operations; laparotomies performed for large ovarian tumours, malignancies and ruptured ectopic pregnancies. Caesarean sections performed for prolong labour, prolong premature rupture membranes, prolonged second stage had more likelihood of development of sepsis. Occurrence of SSI resulted in significant prolongation of hospital stay.

Conclusions: The incidence of SSI in the present study was within acceptable limits. Regular surveillance for SSI in the hospital and sensitization of staff regarding consequences of SSI would go a long way in further reduction in the rate of SSI.
\end{abstract}

Keywords: Gynaecological surgery, Infective morbidity, Surgical site infections

\section{INTRODUCTION}

Post operative infection is a type of healthcare-associated infection, in which a wound infection occurs after an invasive (surgical) procedure. Surgical site infections are frequent; the incidence varies from 0.5 to $15 \%$ depending on the type of operation and health status of patient. ${ }^{1-3}$ It is a significant problem, which limits the potential benefits of surgical interventions. The impact on hospital costs and postoperative extended length of stay (between 3 and 20 additional days) is considerable. ${ }^{4-7}$
The common causes of wound dehiscence are infection at the wound, pressure on sutures, sutures too tight, injury to the wound area, weak tissue or muscle at the wound area, incorrect suture technique used to close operative area, use of high-dose or long-term corticosteroids, severe vitamin $\mathrm{C}$ deficiency (scurvy). Patient with wound infection and dehiscence usually present with symptoms of bleeding from wound, pain at the stitch site, swelling and redness near the stitch site, fever and broken sutures and sometimes there is complete disruption of wound and bowel coming out of the abdominal wall. 
Present study was conducted,

- To study the incidence of surgical site infection (SSI) and dehiscence following Gynaecological surgery.

- To analyze the risk factors associated with surgical site infection and dehiscence.

- To study the microorganisms related with surgical site infection.

\section{METHODS}

It was an observational cross sectional prospective study carried out in a 1250 bedded tertiary care teaching hospital located in rural area of central India for a period of six months

\section{Inclusion criteria}

Inclusion criteria were women of all age groups, who had undergone Gynaecological surgery for different Obstetric or Gynecological indications; operated cases, who developed either surgical site infection and or wound dehiscence.

\section{Exclusion criteria}

Exclusion criteria were complicated and infected cases recently operated at other hospital and required repeat surgery.

Patients needing major or minor Gynecological surgery were admitted three days or one day prior to date of operation respectively. Complete physical examination was carried out to rule out any local or systemic infections. Blood and serological investigations were performed as pre requisite for anaesthesia. All operations were performed either under general anaesthesia or regional anaesthesia by same team of doctors working in the hospital. Being a postgraduate training institute, minor surgeries were performed by trainee resident doctors, under supervision of senior doctors.

All patients received a single dose of prophylactic antibiotic in the form of Inj.Cefotaxime 1 gram and Inj.Metronidazole $500 \mathrm{mgs}$ at 8 am on the day of surgery. Pre-operative skin disinfection was done with germicidal solution (3\%) having combination of chlorhexidinegluconate, cetrimide and isopropyl alcohol solution. Skin was then treated with Povidone iodine solution (10\%). Following surgery, abdominal wall was closed in layers. Rectus sheath was closed with delayed absorbable suture material (Vicryl 1) and skin was closed with nylon (00 Ethilon) suture material. Caesarean section wounds were closed by sub-cuticular delayed absorbable (000 vicryl) suture material. Antibiotics in the form of Inj.Cefotaxime 1 gram intravenously every 12 hourly and Inj. Metronidazole $500 \mathrm{mg}$ every 8 hourly were continued for 24 to 36 hours and then same drugs by oral route for next 7 days.
Following definitions were used in the present study.

a. Febrile morbidity: Febrile episodes of $>38^{\circ} \mathrm{C}$, occurring on two occasions, at least 4 hours apart, after the first 24 hours following the operation.

b. Surgical site sepsis: Graded as (a) erythema and or induration (b) serous oozing (c) the presence of pus

c. Wound dehiscence: Separation of edges of suture line by more than $1 \mathrm{~cm}$ - superficial or deep or complete abdominal wall (Burst abdomen) as per CDC guidelines.

In the absence of any complication, patients were discharged on second postoperative day of laparoscopic minor surgery, third postoperative day of laparoscopic major surgery and eighth day of laparotomy. Cases operated by laparoscopic technique were asked to come for stitch removal on seventh postoperative day. All patients were advised to return for follow-up after two weeks from the date of discharge from hospital.

\section{Data collection}

Sources and Outcome variables- Sources of data collection were hospital records like admission- discharge register, operation theatre register, anesthesia register, indoor case file, treatment register. Data related to various outcome variables like age, body mass index, associated risk factors, indication and nature of surgeryemergency or elective, route and technique of surgery, duration of surgery and anesthesia, intra -operative complications, need for post-operative pain relief, duration of parenteral fluid therapy, need for blood or component therapy, timing of ambulation, infective morbidity, surgical site infections, hospital stay, wound related late complications were collected. Data on above variables was collected in a structured proforma.

\section{Statistical analysis}

Data related to different variables was entered in Microsoft office excel and was analyzed using statistical package for the social sciences (SPSS) version 21. Data was analyzed and compared among different variables using percentages and Z-test of difference between two proportions. $\mathrm{P}$ value less than 0.05 was considered significant

\section{RESULTS}

Majority of cases (70\%) belonged to lower socio economic class with rural residence and education up to primary schooling and with poor health awareness. More than $70 \%$ cases were having mild anaemia at the time of surgery. More than 25\% cases had BMI below 18 and $15 \%$ women had BMI above 25. Pre-operative shaving of abdominal incision site was done as a protocol on day prior to surgery. Prophylactic antibiotics were not 
administered at appropriate time in $30 \%$ cases. Antiseptic and aseptic precautions were not followed by $50 \%$ of the members of surgical team.

Skin disinfection before incision was done hurriedly by the surgeon. Hand scrubbing practices, proper covering of face and head by operating surgeon were unsatisfactory. Many cases were operated in single theatre on one day. It did not give sufficient time for the theatre staff to prepare the theatre for next case properly after each surgery.

Table 1: Incidence of surgical site infection (SSI) / Dehiscence.

\begin{tabular}{|llll|}
\hline $\begin{array}{l}\text { Type of } \\
\text { Surgery }\end{array}$ & $\begin{array}{l}\text { Total } \\
\text { number } \\
\text { of cases } \\
(\mathbf{n}=2031)\end{array}$ & $\begin{array}{l}\text { Number of } \\
\text { cases of } \\
\text { SSI } \\
(\mathbf{n}=57)\end{array}$ & $(\%)$ \\
\hline $\begin{array}{l}\text { Exploratory } \\
\text { Laparotomy }\end{array}$ & 16 & 02 & 12.50 \\
\hline $\begin{array}{l}\text { Total } \\
\text { Abdominal }\end{array}$ & 44 & 03 & 06.81 \\
Hysterectomy & & 3 & 03.03 \\
\hline $\begin{array}{l}\text { Tubal } \\
\text { Ligation/Lap } \\
\text { TL }\end{array}$ & 99 & 48 & 02.59 \\
\hline LSCS & 1852 & 01 & 05.00 \\
\hline $\begin{array}{l}\text { Total } \\
\text { Laparoscopic } \\
\text { Hysterectomy }\end{array}$ & 20 & 01 & \\
\hline
\end{tabular}

Incidence of SSI was highest following laparotomies $(12.50 \%)$ and was lowest with caesarean section $(2.59 \%)$. [By applying Z-test of difference between two proportions, there is significant difference between proportions of SSI in cases undergoing Exploratory Laparotomy as compared to overall incidence of SSI (i.e. $\mathrm{p}<0.05)]$ (Table 1).

Table 2: Risk Factors associated with surgical site infection (Ssi) / Dehiscence.

\begin{tabular}{|l|l|}
\hline Risk factor & $\begin{array}{c}\% \text { of cases of SSI } \\
(\mathbf{n}=57)\end{array}$ \\
\hline Over-weight / Obesity & 46.00 \\
\hline Previous surgical scar & 23.00 \\
\hline Anaemia & 13.00 \\
\hline Under nutrition & 11.00 \\
\hline Gynecological Malignancy & 09.00 \\
\hline Wound hematoma & 06.00 \\
\hline Infective focus & 06.00 \\
\hline Second stage LSCS & 03.00 \\
\hline Immuno-compromised state & 03.00 \\
\hline Diabetes & 02.00 \\
\hline Chronic Diseases (TB) & 01.00 \\
\hline Post- Chemotherapy & 01.00 \\
\hline Unknown & 22.00 \\
\hline
\end{tabular}

Over weight (46\%) and previous laparotomy scar (23\%) were the commonest risk factors associated with postsurgical infections and or wound dehiscence. [By applying Z-test of significance between two proportions, obesity and previous laparotomy scar had statistically significant contribution to SSI in the present study. (i.e. $\mathrm{p}$ $<0.05)$ ] (Table 2).

Forty six percent cases of wound infection had high BMI values. By applying Z-test of difference between two proportions, statistically significant number $(88 \%)$ of cases studied had superficial SSI (Table 3).

Table 3: Distribution of cases of surgical site infection (SSI) / Dehiscence as per type of dehiscence.

\begin{tabular}{|ll|}
\hline $\begin{array}{l}\text { Extent of Dehiscence as per CDC } \\
\text { criteria }\end{array}$ & $\begin{array}{l}\% \text { of cases of } \\
\text { SSI }(\mathbf{n}=57)\end{array}$ \\
\hline $\begin{array}{l}\text { Superficial surgical site infection } \\
\text { (Skin + subcutaneous tissue) }\end{array}$ & 88.00 \\
\hline $\begin{array}{l}\text { Deep surgical site infection } \\
\text { (Muscles and or Fascial sheath) }\end{array}$ & 06.00 \\
\hline $\begin{array}{l}\text { Organ/Space } \\
\text { (Burst abdomen) }\end{array}$ & 06.00 \\
\hline Total & 100 \\
\hline
\end{tabular}

Staphylococcus aureus was the commonest organism isolated in the culture. [By applying Z-test of difference between two proportions, there is a statistical significance between the number of wound cultures positive for Staphylococcus aureus and cultures positive for other microorganisms $(\mathrm{p}<0.05)]$ (Table 4$)$.

Table 4: Micro-organisms isolated in surgical site infections (SSI).

\begin{tabular}{|ll|}
\hline Type of micro-organism & $\begin{array}{l}\% \text { of cases of SSI } \\
(\mathbf{n = 5 7})\end{array}$ \\
\hline Staphylococcus Aureus & 39.00 \\
\hline Klebseilla & 07.00 \\
\hline E.coli & 05.00 \\
\hline Pseudomonas Aeruginosa & 03.00 \\
\hline Acinobacter & 01.00 \\
\hline Diptheroid & 01.00 \\
\hline Enterococci & 01.00 \\
\hline Streptococci & 01.00 \\
\hline Multiple organisms & 10.00 \\
\hline Sterile culture & 32.00 \\
\hline Total & 100 \\
\hline
\end{tabular}

Post-operative febrile morbidity and need for blood transfusion were commonly observed among women, who developed post-operative wound infection and or wound dehiscence (Table 5). In the present study, there were 2 cases of burst abdomen. The risk factors associated with these cases were malignancy in 1cases, obesity, obstructed labour and prolonged PROM, undernutrition in another case. Wound cultures obtained from these cases showed growth of Staphylococcus aureus. 
Table 5: Distribution of cases of surgical site infection (SSI) / Dehiscence as per morbidity and mortality.

\begin{tabular}{|l|l|}
\hline Morbidity/Mortality & $\%$ of cases $(n=57)$ \\
\hline Fever & 30.00 \\
\hline Vomiting & 04.00 \\
\hline Distension of abdomen & 04.00 \\
\hline Delay in ambulation & 07.00 \\
\hline Need for blood transfusion & 16.00 \\
\hline Increased hospital stay & 86.00 \\
\hline Need for ICU management & 00.00 \\
\hline Septic shock / DIC & 00.00 \\
\hline Mortality & 00.00 \\
\hline
\end{tabular}

\section{DISCUSSION}

Nosocomial infections or hospital acquired infections occur worldwide and affect both developed and resourcepoor countries. The highest frequencies of nosocomial infections were reported from hospitals in the Eastern Mediterranean and South-East Asia Regions (11.8 and $10.0 \%$ respectively), with a prevalence of 7.7 and $9.0 \%$ respectively in the European and Western Pacific Regions. ${ }^{8}$

Hospital-acquired infections add to functional disability and emotional stress of the patient and may, in some cases, lead to disabling conditions that reduce the quality of life. Nosocomial infections are also one of the leading causes of death. ${ }^{9}$ The economic costs are considerable. ${ }^{10,11}$ The increased length of stay for infected patients is the greatest contributor to cost. ${ }^{12,7,13}$ One study showed that the overall increase in the duration of hospitalization for patients with surgical wound infections was 8.2 days, ranging from 3 days for Gynaecology to 9.9 for general surgery. ${ }^{14}$

\section{1) Incidence of SSI}

Survey of post-operative wound infection in 150 cases out of 6639 cases was carried out for 12 months at KandangKerbau Hospital, Singapore by J.Y.H. Chia et al. It showed the incidence of wound infection as $2.26 \%$. Incidence of wound infection in Caesarean section was $2.29 \%{ }^{15}$ Operations with lowest wound infection rates were Laparoscopy and sterilization operations. Highest rate of infections was seen in Radical and extended hysterectomies. According to James Mowat et al, the incidence of wound infection in his study was $2.3 \% .^{16}$ Incidence of wound infection noted by Pandit et al in their study, which was carried out retrospectively from March 2002 to January 2003 was $2.76 \% .{ }^{17}$ Incidence of wound infection following Caesarean section studied by Piret Mitt et alin his cross-sectional surveycarried out in tertiary care obstetric and Gynaecological center was $6.2 \% .^{18}$ According to Demisew et al surgical site infection rate in his prospective study on 770 women from April 2009- March 2010 was $11.4 \% .{ }^{19}$ Infection rate following Caesarean section was more than that following Hysterectomy. In the present study, the overall incidence of wound infection was $2.80 \%$, of which incidence of wound infection in exploratory laparotomy was the highest (12.50\%), followed by abdominal hysterectomy $(6.81 \%)$.The incidence of wound infection in tubal ligation was $3.3 \%$ and laparoscopic hysterectomy was $5.0 \%$.

\section{2) Risk factors associated with SSI}

In a study of 15 cases of wound infection out of 3500 cases analyzed retrospectively by John Spiliotis et al in Messologi, Greece, COPD was found in 10 cases $(66.66 \%)$, obesity in 6 cases $(40 \%)$, malnutrition in 5 cases $(33.33 \%)$, anaemia in 6 cases $(40 \%)$, diabetes in 6 cases $(40 \%)$, history of previous radiotherapy or chemotherapy in 6 cases $(40 \%)$ and 3 cases $(20 \%)$ were on steroids. ${ }^{20}$ Waqar et al from Pakisthan institute of medical sciences studied 117 cases from $1^{\text {st }}$ Jan $2002-$ $31^{\text {st }}$ Dec 2002 , out of which obesity was found in $13 \%$, anaemia in $17 \%$ cases, undernutrition in $13 \%$ cases and Malignancies in $15 \%$ of cases. ${ }^{21}$ In the present study the risk factors found were obesity and overweight in $46 \%$, previous scar $23 \%$, anaemia $13 \%$, undernutrition in $11 \%$, malignancies in $9 \%$, previous chemotherapy in $1 \%$ cases.

\section{a) Obesity}

Obese individuals frequently face wound complications; including skin wound infection, dehiscence, hematoma and seroma formation, pressure ulcers, and venous ulcers. In particular, a higher rate of surgical site infection occurs in obese patients. Wound tension increases tissue pressure, reducing micro-perfusion and the availability of oxygen to the wound. ${ }^{22,23}$ The increase in pressure ulcers or pressure-related injuries in obese individuals is also influenced by hypovascularity, since poor perfusion makes tissue more susceptible to this type of injury. Obesity was a risk factor in $40 \%$ and $13 \%$ of cases of SSI studied by John Spiliotis et al and Waqar et al respectively while, in the present study, obesity and overweight was risk factor in $46 \%$ cases of SSI. ${ }^{20,21}$

\section{b) Previous scar}

AdekunleSobande et al performed a retrospective study of 371 patients undergoing repeat ceasarean section in King Khalid university, Saudi Arabia. Incidence of wound dehiscence in this study was $4.12 \% .{ }^{24}$ In the present study, the presence of previous scar was risk factor in $23 \%$ cases of SSI.

\section{c) Under-nutrition}

A well-balanced diet is essential to maintain healthy skin and facilitate wound healing. An adequate intake of proteins is needed to produce collagen during the proliferative phase of healing; fats are required to ensure normal cell formation and carbohydrates provide the energy required during cell division and cell replication. Undernutrition was the risk factor in $33 \%$ cases studied 
by John Spiliotis et al and $13 \%$ cases studied by Waqar et al while, in the present study, it was risk factor in only $11 \%$ cases of SSI. ${ }^{20,21}$

\section{d) Diabetes}

The impaired healing that occurs in individuals with diabetes involves hypoxia, dysfunction in fibroblasts and epidermal cells, impaired angiogenesis and neovascularization, high levels of metalloproteases, damage from ROS, decreased host immune resistance, and neuropathy. In the study carried out by John Spiliontis et al, diabetes was risk factor in $40 \%$ of cases studied while in the present study, it was found in only $2 \%$ of cases that developed SSI. ${ }^{20}$ The lower incidence of diabetes in the study population was responsible for less number of diabetes related complications.

\section{3) Micro organisms associated with SSI}

Amongst 150 cases of wound infection studied by Chia et al, $22.8 \%$ showed no bacterial growth in wound discharge sent for culture and sensitivity and $77.2 \%$ cultures were positive for bacterial growth. ${ }^{15}$ Among the etiologic agents found in this study, staphylococcus aureus was the commonest $58.1 \%$ of which $49.5 \%$ were Methicillin sensitive staphylococcus aureus and $8.6 \%$ were methicillin resistant staphylococcus aureus. This was followed by streptococcus species $10.5 \%$ and klebseilla $9.5 \%$ and most of these organisms showed sensitivity to cloxacillin so cloxacillin was used by them to treat wound infection rather than time honoured Ampicillin and Metronidazole combination. In survey done by Pandit et al, $16.6 \%$ cases culture grew organisms, out of which staphylococcus aureus was the commonest $10 \%$ followed by enterobacter $6.6 \%$ and klebseilla species $3.33 \% .{ }^{17}$ A study of 120 cases was done at University teaching hospital and health care, lle-llf, Nigeria by Shittu A.O et al in which bacteria were isolated in cultures of $62 \%$ cases and $38 \%$ did not show any bacterial association in culture. $^{25}$

Of these $62 \%$ cases, $38.23 \%$ were mono-microbial and $53.92 \%$ were poly-microbial. Staphylococcus was the predominant organism isolated in $25 \%$ cases, followed by e-coli in $12 \%$, pseudomonas aeruginosa in $9 \%$ and staphylococcus epidermidis in $9 \%$ cases. In the present study, in $68 \%$ cases cultures showed bacterial growth and in $32 \%$ they were sterile. Out of those showing bacterial growth, $90 \%$ were mono-microbial and $10 \%$ were polymicrobial. Predominant micro-organism isolated was staphylococcus aureus in $39 \%$ cases, klebseilla in $7 \%$, Ecoli in $5 \%$, Pseudomonas aeruginosa in $3 \%$, and acinobacter, diptheroid, streptococcus and enterococci each in $1 \%$ cases. Staphylococcus aureus was found sensitive to penicillin group of drugs, mainly cloxacillin and erythromycin. Gram negative organisms were sensitive to gentamycin.

\section{6) Post-operative morbidity and mortality of patients developing SSI}

In the survey done by James Mowat et al, post-operative febrile and increased hospital stay was commonly observed. One of the patients in the series died with a pulmonary embolism on the fifteenth postoperative day. ${ }^{16}$ In a survey done by John Spiliotis et al, delayed ambulation, increased hospital stay and need for blood transfusion were commonly observer. ${ }^{20}$ All patients with wound dehiscence were re-operated after the wound dehiscence was diagnosed and three of them (20\%) died due to postoperative complication of reoperation, in one of them recurrence of wound dehiscence was observed. Regarding the preoperative risk factors, three out of four $(75 \%)$ patients with 7 or more risk factors did die. In the present study, we observed that, post-operative febrile morbidity, need for blood transfusion, delay in ambulation and increased hospital stay were the commonly observed consequences of SSI. There was no mortality due to SSI in the present study.

\section{CONCLUSION}

The incidence of SSI in the present study was within acceptable limits. Presence of patient related high risk factors like overweight, anemia, previous laparotomy scars and factors responsible for sub optimal operation theatre environment, like high humidity, large patient turnover, below standard sterilization of the equipments and poorly followed aseptic and antiseptic measures by health care workers, were responsible for development of SSI. The majority of surgical site infections can be prevented by the pre-, intra- and postoperative phases of care. Surgical site infections have a significant effect on quality of life of the patient. They are associated with considerable morbidity and extended hospital stay. In addition, surgical site infections result in a considerable financial burden to healthcare providers. Regular surveillance for SSI in the hospital and sensitization of staff regarding consequences of SSI would go a long way in further reduction in the rate of SSI.

\section{ACKNOWLEDGMENTS}

We acknowledge Pravara Institute of Medical Sciences (Deemed University) for permitting us to conduct this study at Pravara Rural Hospital.

Funding: No funding sources

Conflict of interest: None declared

Ethical approval: The study was approved by the Institutional Ethics Committee

\section{REFERENCES}

1. Cruse PJE, Ford R. The epidemiology of wound infection. A 10 year prospective study of 62,939 wounds. Surg Clin North Am. 1980;60:27-40. 
2. Horan TC, Culver DH, Gaynes RP, Jarvis WR, Edwards JR, Reid CR.. Nosocomial infections in surgical patients in the United States, 1986-1992 (NNIS). Infect Control Hosp Epidemiol. 1993;14:7380 .

3. Hajjar J, Bavey A, Pinzaru G, Coiron M, Fabry J. Réseau ISO Sud-Est: un an de surveillance des infections du site opératoire. Bulletin Èpidémiologique Hebdomadaire. 1996;42.

4. Brachman PS, Dan BB, Haley RW, Hooton TM, Garner JS, Allen JR. Nosocomial surgical infections: incidence and cost. Surg Clin North Am. 1980;60:15-25.

5. Fabry J, Meynet R, Joron MT, Sepetjan M, Lambert DC, Guillet R. Cost of nosocomial infections: analysis of 512 digestive surgery patients. World J Surg. 1982;6:362-5.

6. Prabhakar P, Raje D, Castle D, Rao B, Fletcher P, Duquesnay D, et al. Nosocomial surgical infections: incidence and cost in a developing country. Am Jinfect Control. 1983;11:51-6.

7. Kirkland KB. The impact of surgical-site infections in the 1990's: attributable mortality, excess length of hospitalization and extra costs. InfectControl HospEpidemiol, 1999; 20:725-730.

8. Mayon-White RT, Ducel G, Kereselidze T, Tikomirov E. An international survey of the prevalence of hospitalacquired infection. J Hosp Infect. 1988;11(Supplement A):43-8.

9. Ponce-de-Leon S. The needs of developing countries and the resources required. J Hosp Infect. 1991;18 (Supplement):376-81.

10. Plowman R. The socio-economic burden of hospitalacquired infection. Euro Surveill. 2000;5(4):49-50.

11. Wenzel RP. The economics of nosocomial infections. J Hosp Infect. 1995;31:79-87.

12. Pittet D, Taraara D, Wenzel RP. Nosocomial bloodstream infections in critically ill patients. Excess length of stay, extra costs, and attributable mortality. JAMA. 1994;271:1598-601.

13. Wakefield DS, Helms CM, Massanari RM, Mori M, Pfaller M. Cost of nosocomial infection: relative contributions of laboratory, antibiotic, and per diem cost in serious Staphylococcus aureus infections. Amer J Infect Control. 1988;16:185-92.
14. Coello R, Glenister H, Fereres J, Bartlett C, Leigh D, Sedgwick $J$, et al. The cost of infection in surgical patients: a case study. J Hosp Infect. 1993;25:239-50.

15. Chia JY, Tan KW, Tay L. A survey of post-operative wound infections in obstetrics and gynaecology: the Kandang Kerbau Hospital experience. Singapore Med J. 1993;34:221-4.

16. Mowat J, Bonnar J. Abdominal wound dehiscence after caesarean section. British Med J. 1971;2:256-7.

17. Pandit A, Sharma $P$, Yangzom K. Incidence of caesarean wound infection in patan hospital, Nepal $\mathrm{J}$ Nepal med assoc. 2003;42:280-3.

18. Mitt P, Lang K, Peri A, Maimets M. Surgical-site infections following cesarean section in an Estonian university hospital: postdischarge surveillance and analysis of risk factors. Infect Control Hosp Epidemiol. 2005;26(5):449-54

19. Amenu D, Belachew T, Araya F. Surgical site infection rate and risk factors among obstetric cases of jimma university specialized hospital, southwest Ethiopia. Ethiop J Health Sci. 2011;21(2):91-100.

20. Spiliotis J. Wound dehiscence: is still a problem in the 21th century: a retrospective study. World J Emergency Surg. 2009;4:12.

21. Waqar. Study of wound infection in Pakisthan institute of medical sciences. Ulus trauma. 2001;7(2):96-9.

22. Wilson JA, Clark JJ. Obesity: impediment to postsurgical wound healing. Adv Skin Wound Care. 2004;17:426-35.

23. Anaya DA, Dellinger EP. The obese surgical patient: a susceptible host for infection. Surg Infect (Larchmt). 2006;7:473-80.

24. Sobande A, Eskandar M. Multiple repeat caesarean section: Complications and outcome. J Obstet Gynecol Can. 2006;8(3):193-7.

25. Shittu AO, Kolawole DO, Oyedepo EAR. A study of wound infections in two health institutions in lle-llf, Nigeria. Afr J Biomed Res. 2002;5:97-102.

Cite this article as: Gavhane SP, Bangal VB, Gagare SD, Kodlikeri AR. Study of infective morbidity following gynecological surgeries. Int J Reprod Contracept Obstet Gynecol 2018;7:2322-7. 